\title{
OPTIMAL BAND RATIO ANALYSIS OF WORLDVIEW-3 IMAGERY FOR BATHYMETRY OF SHALLOW RIVERS (CASE STUDY: SARCA RIVER, ITALY)
}

\author{
M. Niroumand-Jadidi ${ }^{\text {a, }}{ }^{*}$, A. Vitti $^{\text {a }}$ \\ ${ }^{\text {a }}$ Department of Civil, Environmental and Mechanical Engineering, University of Trento, Via Mesiano, 77 - 38123 Trento, Italy - \\ (m.niroumand, alfonso.vitti)@unitn.it \\ ${ }^{\mathrm{b}}$ Department of Biology, Chemistry and Pharmacy, Freie Universität Berlin, Altensteinstraße 6, 14195 Berlin, Germany - \\ (m.niroumand@fu-berlin.de)
}

Commission VIII, WG VIII/4

KEY WORDS: Bathymetry, River, Optimal Band Ratio Analysis, WorldView-3, GeoEye, Spectral Bands

\begin{abstract}
:
The Optimal Band Ratio Analysis (OBRA) could be considered as an efficient technique for bathymetry from optical imagery due to its robustness on substrate variability. This point receives more attention for very shallow rivers where different substrate types can contribute remarkably into total at-sensor radiance. The OBRA examines the total possible pairs of spectral bands in order to identify the optimal two-band ratio that its log transformation yields a strong linear relation with field measured water depths. This paper aims at investigating the effectiveness of additional spectral bands of newly launched WorldView-3 (WV-3) imagery in the visible and NIR spectrum through OBRA for retrieving water depths in shallow rivers. In this regard, the OBRA is performed on a WV-3 image as well as a GeoEye image of a small Alpine river in Italy. In-situ depths are gathered in two river reaches using a precise GPS device. In each testing scenario, 50\% of the field data is used for calibration of the model and the remained as independent check points for accuracy assessment. In general, the effect of changes in water depth is highly pronounced in longer wavelengths (i.e. NIR) due to high and rapid absorption of light in this spectrum as long as it is not saturated. As the studied river is shallow, NIR portion of the spectrum has not been reduced so much not to reach the riverbed; making use of the observed radiance over this spectral range as denominator has shown a strong correlation through OBRA. More specifically, tightly focused channels of rededge, NIR-1 and NIR-2 provide a wealth of choices for OBRA rather than a single NIR band of conventional 4-band images (e.g. GeoEye). This advantage of WV-3 images is outstanding as well for choosing the optimal numerator of the ratio model. Coastal-blue and yellow bands of WV-3 are identified as proper numerators while only green band of the GeoEye image contributed to a reliable correlation of image derived values and field measured depths. According to the results, the additional and narrow spectral bands of WV-3 image lead to an average determination coefficient of $67 \%$ in two river segments, which is $10 \%$ higher than that of obtained from the 4-band GeoEye image. In addition, RMSEs of depth estimations are calculated as $4 \mathrm{~cm}$ and $6 \mathrm{~cm}$ respectively for WV-3 and GeoEye images, considering the optimal band ratio.
\end{abstract}

\section{INTRODUCTION}

Remote sensing has the potential for extraction of spatially and temporally explicit bathymetric information. This type of information would have a significant contribution to hydraulic analysis, studying flow dynamics and prediction of probable hazards, changes in fluvial systems, habitat modelling, pollutants distribution modeling, planning and management of restoration issues (Marcus et al., 2003; Fonstad and Marcus, 2005; Parasiewicz, 2007; Flener, 2013). Apart from wide range of studies in the area, particularly on marine and coastal applications, Legleiter et al. (2009) carried out the feasibility assessment on bathymetry of streams from satellite imagery with a study on gravel-bed rivers. Taking the advantages of high spatial resolution satellite imagery is of particular importance for studying small rivers and streams (Leckie et al., 2005; Legleiter et al., 2002). WorldView-2 (WV-2) launched in late 2009 is the first satellite which provides a unique combination of high spatial and spectral resolutions (DigitalGlobe, 2009). In contrast to other high spatial resolution sensors (e.g. IKONOS, QuickBird, GeoEye, WorldView-1) which have mainly low spectral resolutions, WV-2 provides eight spectral bands ranging from visible $(400 \mathrm{~nm})$ to near-infrared $(1040 \mathrm{~nm})$. In this regard, besides traditional RGB-NIR bands, four new spectral bands have been added which include coastal blue
(400-450 nm), yellow $(585-625 \mathrm{~nm})$, red-edge $(705-745 \mathrm{~nm})$ and NIR2 (860-1040 nm). In this research, the efficiency of WV-3, launched in 2014, is examined for bathymetry of shallow rivers. This satellite sensor provides eight additional spectral bands in Short Wave Infrared (SWIR) with respect to WV-2. However, eight bands of the WV-3 image with the same spectral specifications of WV-2 imagery are considered. In addition, a GeoEye image of the same area is used to have a better understanding about the role of additional spectral channels of WV-2/WV-3 in bathymetry of shallow rivers.

The bathymetric models usually employ single band (Lyzenga, 1978) or two-band ratio (Stumpf et al. 2003; Legleiter et al., 2004) to estimate the water depth from optical imagery. In this research, the advanced method of OBRA (Legleiter et al., 2009) is applied on both WV-3 and GeoEye imagery of a small river to evaluate their spectral bands in terms of water depth estimation. The OBRA identifies the optimal pair of spectral bands for which the log transformation of their ratio provides the highest linear correlation with water depths.

The methodology of OBRA, its potential advantages and the calibration process are presented in Section 2. Section 3 describes the study area, imagery and in-situ measurements. The 
results of implementations are provided in Section 4. Finally, concluding remarks are made in Section 5.

\section{METHODOLOGY}

\subsection{Optimal Band Ratio Analysis (OBRA)}

To remove the effect of substrate variability, one can use the ratio of bottom radiances in two different wavelengths (Equation 1), which remains almost constant across substrate types (Stumpf et al. 2003; Dierssen et al., 2003; Legleiter et al., 2009; Legleiter et al., 2004).

$$
X=\ln \left[\frac{R_{b}\left(\lambda_{1}\right)}{R_{b}\left(\lambda_{2}\right)}\right]
$$

where

$X=$ image-derived value

$\mathrm{R}_{\mathrm{b}}\left(\lambda_{1}\right), \mathrm{R}_{\mathrm{b}}\left(\lambda_{2}\right)=$ bottom radiance in spectral bands corresponding to wavelengths $\lambda_{1}$ and $\lambda_{2}$

Stumpf et al. (2003) demonstrated that different substrates at the same depth have approximately equal ratio values. The main advantage of this approach would be its less sensitivity to the substrate type, as the ratio of bottom reflectance remains almost the same for all benthic cover types (Stumpf et al. 2003; Dierssen et al., 2003). Therefore, the ratio-based techniques can reduce the undesirable effect of substrate variability and may lead to more precise modeling of bathymetry in rivers with complex bed types and roughness circumstances. This technique has been applied in shallow coastal waters (Dierssen et al., 2003; Stumpf et al., 2003) and it is receiving more attention in remote sensing of rivers regarding the considerable influence of substrate in total at-sensor radiance in shallow waters. However, specific bands satisfy this assumption much more efficiently than others. The optimal pair of spectral bands depends on the range of water depths and also substrate types available in the stream channel (Legleiter et al., 2004). In this way, Legleiter et al., (2009) proposed an Optimal Band Ratio Analysis (OBRA) in order to identify the best pair of spectral bands which is less sensitive to substrate variability and consequently yields a stronger linear relation with water depths. Towards this end, regression between image derived values $(X)$ and water depths $(d)$ shall be performed for different two-bytwo combinations of bands and a pair would be selected as optimal one which yields the highest coefficient of determination $\left(R^{2}\right)$.

\subsection{Calibration of the Model}

Calibration of bathymetric models, either single band or twoband ratio techniques, is critical to form an appropriate linear relation between image derived values and water depths across all image pixels (Equation 2).

$$
d=a X+b
$$

$$
\begin{aligned}
& X=\text { image-derived value } \\
& d=\text { water depth } \\
& a, b=\text { unknown parameters of the linear model }
\end{aligned}
$$

Empirical calibration is the widely used approach for estimation of unknown parameters of brightness-depth relation (i.e. $a$ and $b)$. In this regard, field measurements of water depth shall be carried out for a limited number of points inside the river channel. Then unknown parameters of the linear model can be estimated by assigning the corresponding image values to the measured depths (Fonstad and Marcus, 2005; Legleiter et al., 2009).

\section{STUDY AREA AND DATA USED}

Sarca river located in northeast of Italy is considered as the case study (Figure 1). Sarca is a small Alpine river that the mean width of channel is about $30 \mathrm{~m}$. The 8-band image of WV-3 as well as the 4-band GeoEye image are used for bathymetric analysis. About 1500 points are recorded as cross-sectional measurements in two segments of the river (Figure 2). This data is used for calibration of the OBRA and also accuracy assessment.

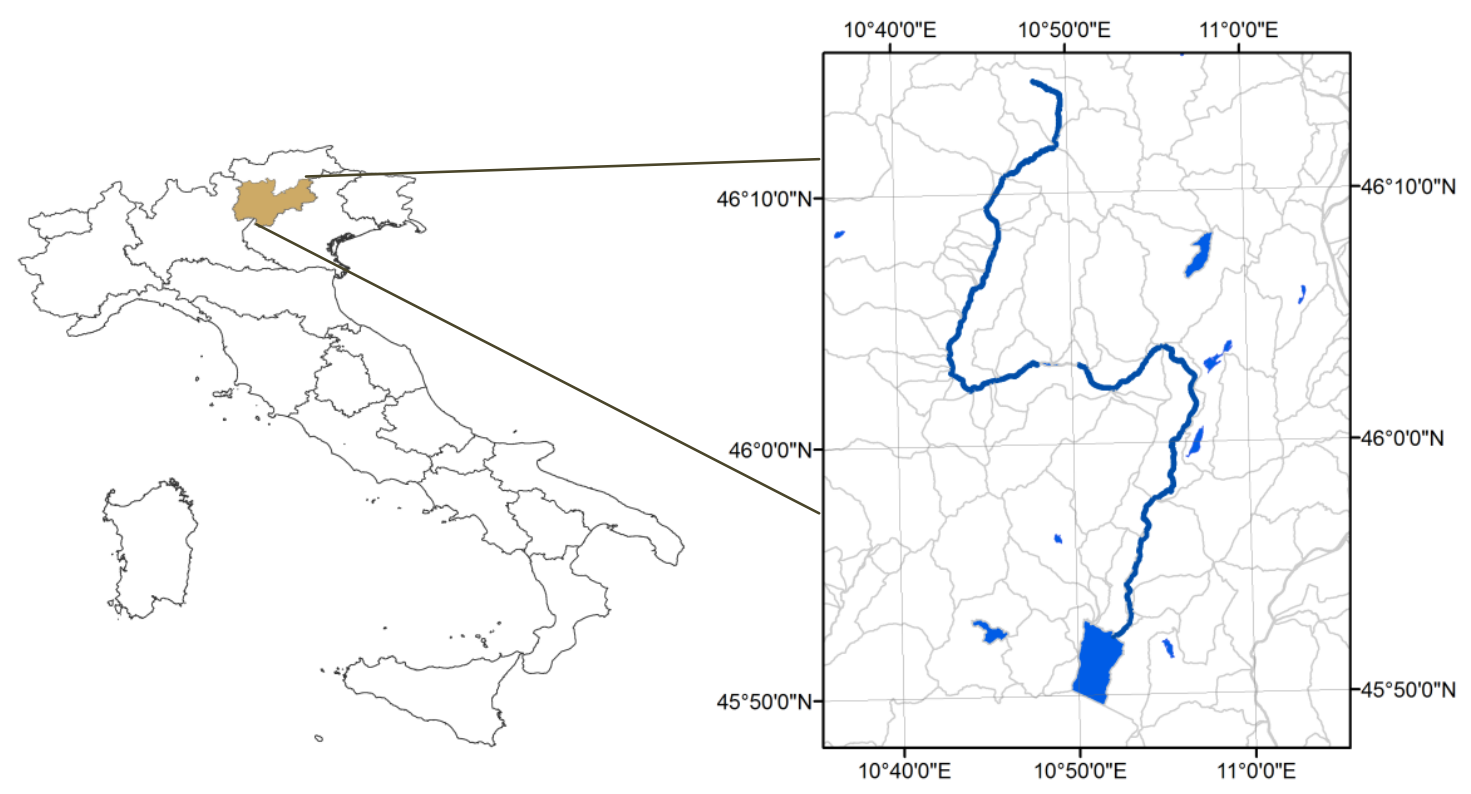

Figure 1. Sarca river located in northeast of Italy 


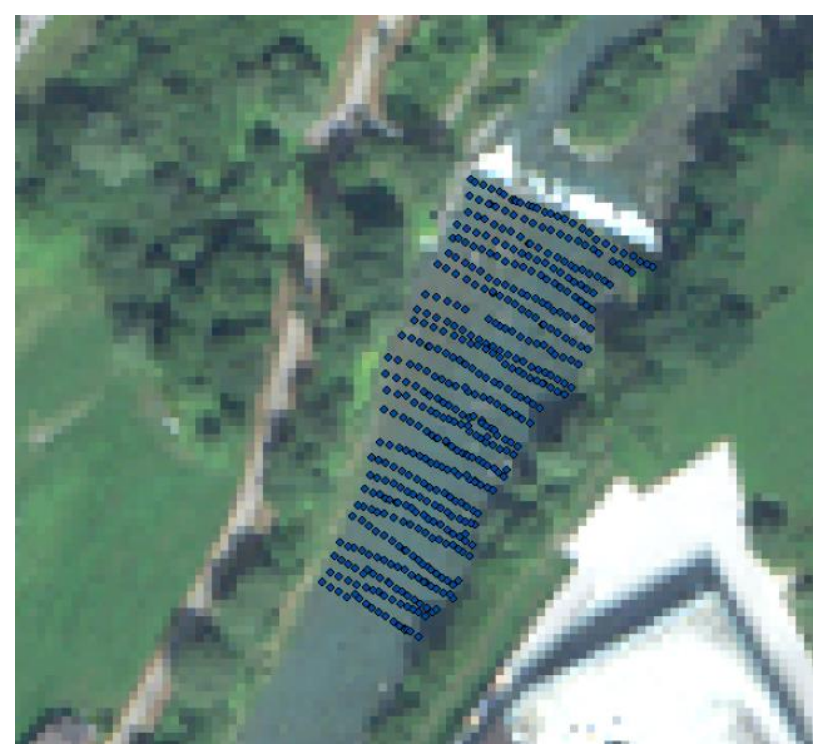

Figure 2. In-situ measurements of water depths in a reach of Sarca river superimposed on true colour composition of the WV-3 image

\section{RESULTS}

The OBRA is performed on satellite imagery and the results are illustrated as a matrix of $R^{2}$ which represents the coefficient of determination values for different pairs of wavelengths (Figure 3 and Figure 4). The row and column numbers of matrixes are respectively the number of spectral channels used as numerators and denominators of the ratio model. Independent checkpoints are used for estimation of the $R^{2}$ values.

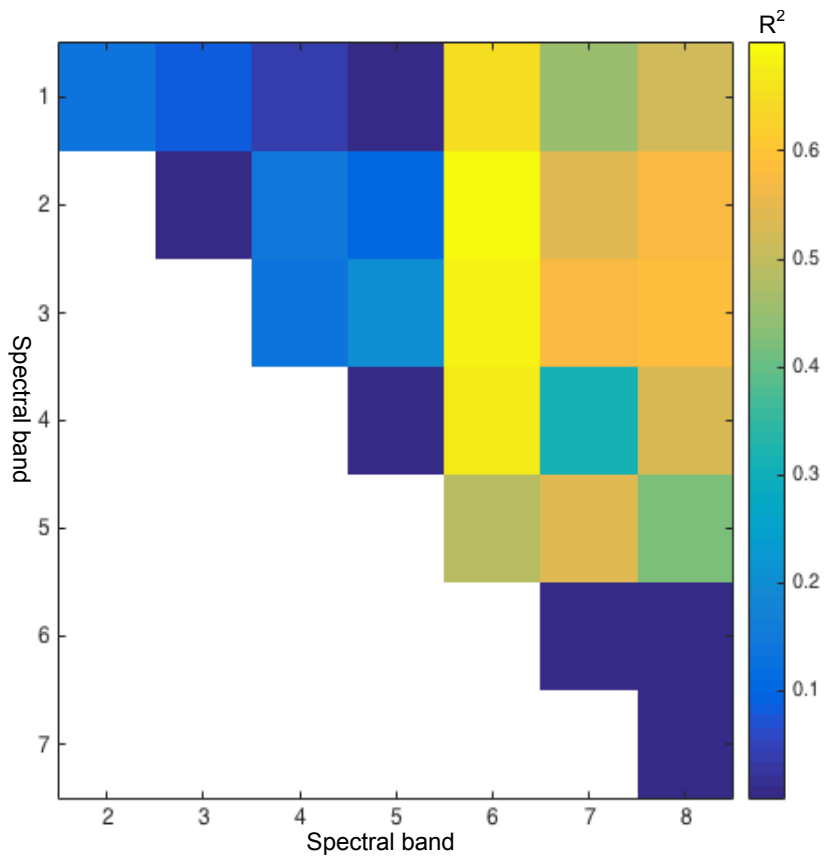

Figure 3. Optimal Band Ratio Analysis (OBRA) using WV-3 image

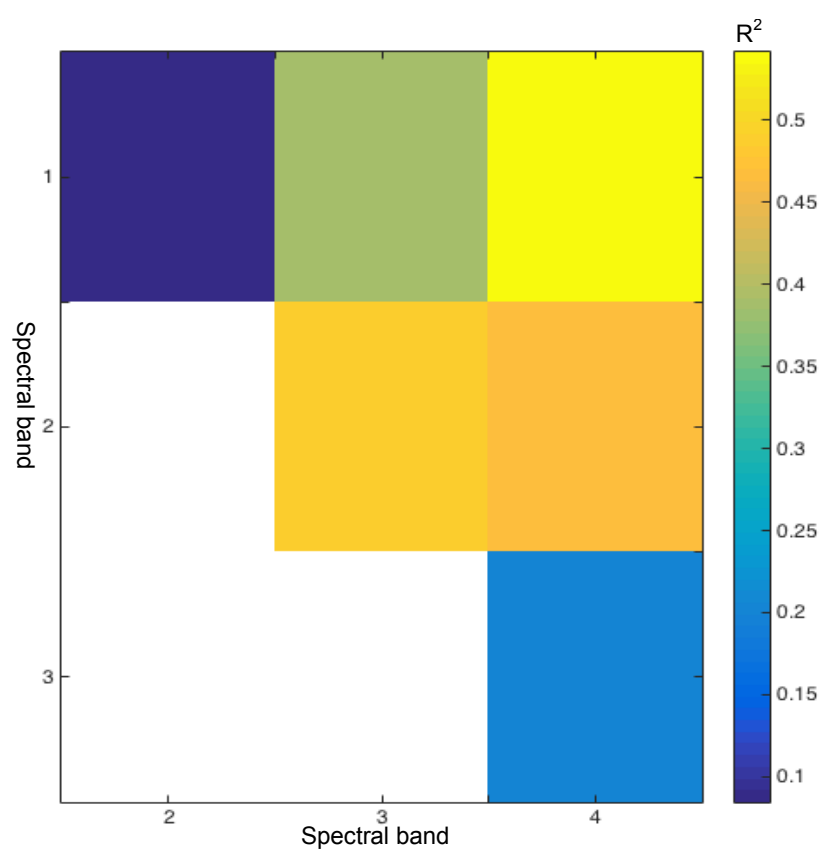

Figure 4. Optimal Band Ratio Analysis (OBRA) using GeoEye image

The best numerator and denominator can be identified for each of images based on the corresponding $R^{2}$ matrix. According to the matrixes, the highest values are concentrated in a specific part of matrix which reveals that certain bands yield a higher level of bathymetric information when using them as numerator or denominator of the ratio model. For instance, longer wavelengths (i.e. red-edge or NIR) are appropriate spectral channels for denominator of the ratio model in this case study. $R^{2}$ and RMSE of depth estimation using the optimal pair of spectral bands are presented in Table (1) for both WV-3 and GeoEye images.

\begin{tabular}{|l|c|c|}
\hline Satellite Sensor & \multicolumn{2}{|c|}{ Accuracy Assessment } \\
\hline & $\mathrm{R}^{2}(\%)$ & RMSE $(\mathrm{cm})$ \\
WV-3 & 67.4 & 4 \\
GeoEye & 57.6 & 6 \\
\hline
\end{tabular}

Table 1. Accuracy statistics of the OBRA for the best pair of spectral bands

The bathymetric maps obtained from the OBRA are illustrated in Figure (5) in comparison to the reference map resultant from the interpolation of in-situ measurements. As it can be inferred from the maps, the bathymetric map of WV-3 image is morphologically appealing rather than that of GeoEye image. 


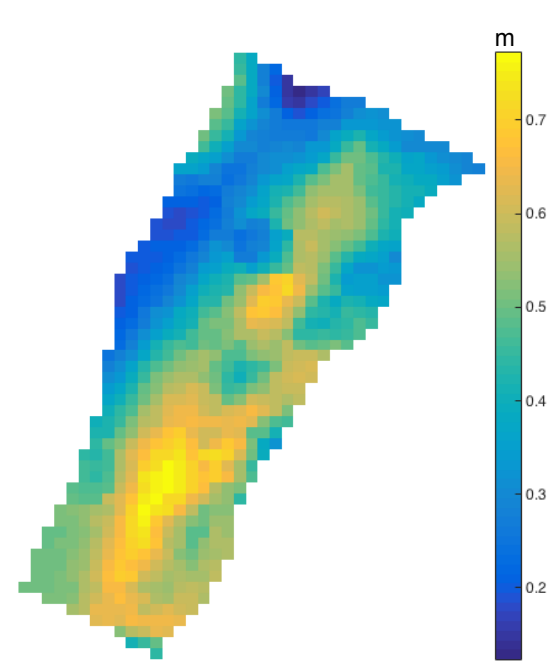

(a)

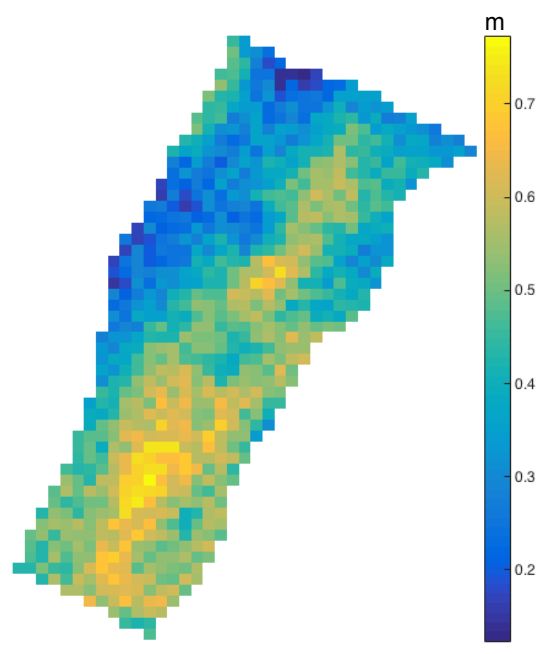

(b)

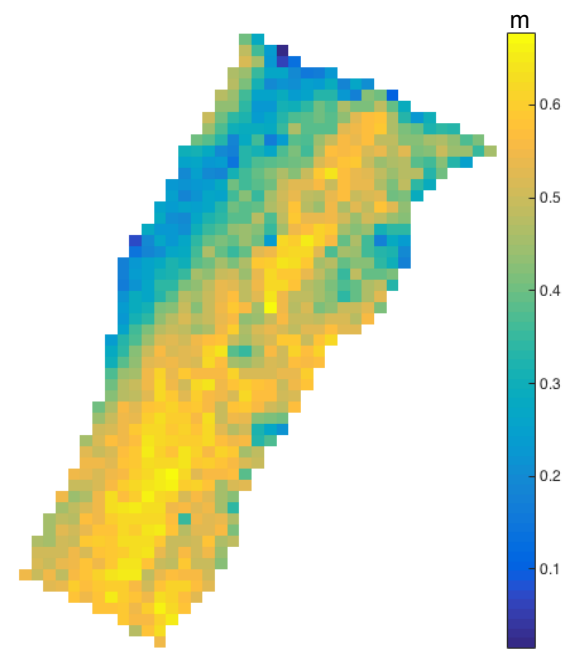

(c)

Figure 5. Comparison of the (a) in-situ depths with the bathymetric maps obtained from OBRA of (b) WV-3 and (c) GeoEye images

\section{CONCLUSIONS}

The OBRA employs all the possible pair of spectral bands in order to make a linear relation between $\log$ transformed ratio values and the water depths. Then the pair of bands which yields to the strongest correlation can be used for bathymetric mapping of all water pixels. In this research, the potential of 8band WV-3 images in the visible and near-infrared spectrum is compared with the traditional 4-band images of GeoEye in terms of bathymetry of a shallow and small river in Italy. As the studied river is shallow (depth $<1 \mathrm{~m}$ ) and clear enough, the NIR bands have not reached the saturation point and they have been identified as the best denominators of the ratio model using both WV-3 and GeoEye images. However, the red-edge and NIR-2 bands of WV-3 image provide more options for using as denominator through the OBRA. Moreover, as it is clear from the $R^{2}$ matrixes (Figure 3 and Figure 4), the additional bands of WV -3 provides a wealth of options for using as numerator. In this regard, using each of band 1 (coastal blue), band 2 (blue), band 3 (green) or band 4 (yellow) as numerator of the ratio model yields to quite high $R^{2}$ values. This is while the GeoEye image provides only blue and green bands for using as numerator. Consequently, using the best pair of bands obtained from OBRA, WV-3 image improved about $10 \%$ the $R^{2}$ of depth estimations as well as the RMSE for $2 \mathrm{~cm}$.

\section{ACKNOWLEDGEMENTS}

This work was carried out within the SMART Joint Doctorate (Science for the MAnagement of Rivers and their Tidal systems) funded with the support of the Erasmus Mundus programme of the European Union. Likewise, we would appreciate the imagery grant awarded by DigitalGlobe Foundation which made the GeoEye image available for our research.

\section{REFERENCES}

Dierssen, H. M., Zimmerman, R. C., Leathers, R. A., Downes, T. V., and Davis, C. O., 2003. Ocean color remote sensing of seagrass and bathymetry in the Bahamas Banks by highresolution airborne imagery. Limnology and Oceanography, 48, pp. 444-455.
DigitalGlobe, 2009. White Paper: the benefits of the 8 spectral bands of WorldView-2. pp: 1-10.

Flener, C., 2013. estimating deep water radiance in shallow water: adapting optical bathymetry model- ling to shallow river environments. Boreal Env. Res, 18, pp. 488-502.

Fonstad, M. A., and Marcus, W. A., 2005. Remote sensing of stream depths with Hydraulically Assisted Bathymetry (HAB) models. Geomorphology, 72(1-4), pp. 320-339.

Leckie, D.G., Cloney, Ed., Jay, C., and Paradine, D., 2005. Automated Mapping of Stream Features with High-Resolution Multispectral Imagery: An Example of the Capabilities, Photogrammetric Engineering \& Remote Sensing, 71(2), pp. 145-155.

Legleiter, C. J., Roberts, D. A. and Lawrence, R. L., 2009. Spectrally based remote sensing of river bathymetry. Earth Surface Processes and Landforms, 34, pp. 1039-1059.

Legleiter, C.J., Marcus, W.A. and Lawrence, R.L. 2002. Effects of sensor resolution of mapping in-stream habitats. Photogrammetric Engineering \& Remote Sensing, 68(8): pp. 801-807.

Legleiter, C.J., Roberts, D.A., Marcus, W.A. and Fonstad, M.A. 2004. Passive optical remote sensing of river channel morphology and in-stream habitat: physical basis and feasibility. Remote Sensing of Environment, 93(4), pp. 493-510.

Lyzenga, D. R., 1978. Passive remote-sensing techniques for mapping water depth and bottom features. Applied Optics, 17, pp. 379-383.

Marcus, W.A., C.J. Legleiter, R.J. Aspinall, J.W. Boardman, and R.L. Crabtree, 2003. High spatial resolution hyperspectral mapping of in-stream habitats, depths, and woody debris in mountain streams, Geomorphology, 53(1-4), pp. 363-380.

Parasiewicz P., 2007. The MesoHABSIM model revisited. River Research and Applications, 23, pp. 893-903.

Stumpf, R. P., Holderied, K., and Sinclair, M., 2003. Determination of water depth with high-resolution satellite imagery over variable bottom types. Limnology and Oceanography, 48, pp. 547-556. 